\title{
Dynamics of photosynthetic photon flux density (PPFD) and estimates in coastal northern California
}

\author{
Shaokui Ge • Richard G. Smith • \\ Constantinos P. Jacovides • Marc G. Kramer • \\ Raymond I. Carruthers
}

Received: 23 October 2009 / Accepted: 24 October 2010 / Published online: 15 December 2010

(C) The Author(s) 2010. This article is published with open access at Springerlink.com

\begin{abstract}
Plants require solar radiation for photosynthesis and their growth is directly related to the amount received, assuming that other environmental parameters are not limiting. Therefore, precise estimation of photosynthetically active radiation (PAR) is necessary to enhance overall accuracies of plant growth models. This study aimed to explore the PAR radiant flux in the San Francisco Bay Area of northern California. During the growing season (March through August) for 2 years 2007-2008, the on-site magnitudes of photosynthetic photon flux densities (PPFD) were investigated and then processed at both the hourly and daily time scales. Combined with global solar radiation $\left(R_{\mathrm{S}}\right)$ and simulated extraterrestrial solar radiation, five PARrelated values were developed, i.e., flux density-based PAR (PPFD), energy-based PAR (PARE), from-flux-to-energy
\end{abstract}

S. Ge $\cdot$ R. G. Smith $\cdot$ R. I. Carruthers $(\bowtie)$

USDA-Agricultural Research Service, Western Regional

Research Center, Exotic and Invasive Weeds Research Unit, 800 Buchanan Street,

Albany, CA 94710, USA

e-mail: ray.carruthers@ars.usda.gov

S. Ge $\cdot$ M. G. Kramer

Department of Earth and Planetary Sciences,

University of California,

Santa Cruz, CA 95064, USA

C. P. Jacovides

Department of Environmental Physics \& Meteorology,

University of Athens,

University Campus, Builds. PHYS-V,

Athens 15784, Greece

Present Address:

R. G. Smith

Department of Natural Resources and the Environment,

University of New Hampshire,

Durham, NH 03824, USA conversion efficiency (fFEC), and the fraction of PAR energy in the global solar radiation (fE), and a new developed indicator - lost PARE percentages (LPR) — when solar radiation penetrates from the extraterrestrial system to the ground. These PAR-related values indicated significant diurnal variation, high values occurring at midday, with the low values occurring in the morning and afternoon hours. During the entire experimental season, the overall mean hourly value of fFEC was found to be $2.17 \mu \mathrm{molJ}^{-1}$, while the respective $\mathrm{fE}$ value was 0.49 . The monthly averages of hourly fFEC and $\mathrm{fE}$ at the solar noon time ranged from 2.15 in March to $2.39 \mu^{m o l J}{ }^{-1}$ in August and from 0.47 in March to 0.52 in July, respectively. However, the monthly average daily values were relatively constant, and they exhibited a weak seasonal variation, ranging from $2.02 \mathrm{~mol}$ $\mathrm{MJ}^{-1}$ and 0.45 (March) to $2.19 \mathrm{molMJ}^{-1}$ and 0.48 (June). The mean daily values of fFEC and $\mathrm{fE}$ at the solar noon were $2.16 \mathrm{molMJ}^{-1}$ and 0.47 across the entire growing season, respectively. Both PPFD and the ever first reported LPR showed strong diurnal patterns. However, they had opposite trends. PPFD was high around noon, resulting in low values of LPR during the same time period. Both were found to be highly correlated with global solar radiation $R_{\mathrm{S}}$, solar elevation angle $h$, and the clearness index $K_{\mathrm{t}}$. Using the best subset selection of variables, two parametric models were developed for estimating PPFD and LPR, which can easily be applied in radiometric sites, by recording only global solar radiation measurements. These two models were found to be involved with the most commonly measured global solar radiation $\left(R_{\mathrm{S}}\right)$ and two large-scale geometric parameters, i.e., extraterrestrial solar radiation and solar elevation. The models were therefore insensitive to local weather conditions such as temperature. In particular, with two test data sets collected in USA and Greece, it was verified that the models could be extended 
across different geographical areas, where they performed well. Therefore, these two hourly based models can be used to provide precise PAR-related values, such as those required for developing precise vegetation growth models.

\section{Introduction}

Photosynthetically active radiation (PAR) is often regarded as the portion of the solar spectrum extending from 0.4 to $0.7 \mu \mathrm{m}$ (McCree 1972; Alados and Alados-Arboledas 1999; Jacovides et al. 2004). PAR is important as it is the sole energy source used by plants for photosynthesis reactions that partially convert physical solar energy into bioenergy-carrying biomass (Mariscal et al. 2000; Tsubo and Walker 2005; Myers 2005). Precise estimation of incident PAR is therefore essential in assessing and modeling plant growth and biological production management in different vegetative ecosystems (Alados and Alados-Arboledas 1999). Such estimation could be integrated with plant growth models and decision-making systems to optimize vegetation management activities and solar energy conversion efficiency into bioenergy-loading biomass (Spitters et al. 1986; Papaionnou et al. 1993; Alados et al. 1996; Gueymard 2000).

Even though PAR is extremely important, it is often not measured in most meteorological stations around the world; therefore, it has to be estimated from the commonly measured global solar radiation $\left(R_{\mathrm{S}}\right)$. As a result, PAR is usually estimated with other measured variables as follows, using one of three approaches: (a) the fractional energy of PAR to global solar radiation (fE; Kvifte et al. 1983; Papaionnou et al. 1993; Udo and Aro 1999; Mõttus et al. 2001; Tsubo and Walker 2005), (b) the fraction of photon flux/energy conversion of PAR (fFEC; Alados et al. 1996; Udo and Aro 1999, 2000; Alados et al. 1996; Alados and Alados-Arboledas 1999; Al-Shooshan 1997; Finch et al. 2004; Jacovides, et al. 2004, 2007), or (c) the PAR photon flux density (PPFD; McCree 1966; Papaionnou et al. 1993; Alados et al. 1996; Jacovides et al. 2004). Such processes were driven by different quantitative methods (McCree 1972; McCartney 1978; Udo and Aro 1999), and each method has its positive and negative attributes.

Use of these models, however, varies with location and season (Stigter and Musabilha 1982; Udo and Aro 1999). It is thus required that such methods be recalibrated to account for local climatic characteristics before application. Relatively long-term measures, such as yearly and seasonally, daily averaged fE values, are not significantly affected by upper atmospheric and lower tropospheric conditions, but the day-to-day differences in these values apparently vary with cloud conditions (McCree 1966; Szeicz 1974; Britton and Dodd 1976; Papaionnou et al. 1993). Therefore, average daily and/or monthly values of $\mathrm{fE}$ are often used, even though $\mathrm{fE}$ is not a constant (Stigter and Musabilha 1982). As such, diurnal PAR variability is often ignored, even though it is known to be an important factor associated with eco-physiological processes of plants, e.g., photosynthesis, photoinhibition, and net ecosystem energy exchange (Mohotti and Lawlor 2002; Misson et al. 2005). The diurnal changes of PAR-related values thus could help to more precisely estimate light use efficiency when building energy-derived plant growth models and for other activities that require detailed assessments of photosynthetic radiation levels.

In the past, PAR was roughly estimated as approximately half of the amount of incident global solar, producing errors too large for estimating plant growth accurately. However, more precise estimation of PAR is required for plant growth models and decision-making systems when they involve detailed management practices, such as the prediction of biological controls, irrigation requirements, and/or needed fertilization rates (Goudriaan and van Laar 1994; Asner and Wessman 1997; Mariscal et al. 2000); otherwise, the accumulated errors can be problematic and costly. To date, estimation of PAR has almost totally focused on estimation of incident PAR flux on the ground surface and above the vegetation canopy directly from the ground-based global solar radiation. However, when light penetrates the air, it is affected by several atmospheric processes such as Rayleigh scattering, water vapor and ozone absorption, and aerosol loadings (Misson et al. 2005; Jacovides et al. 2007). Apparently, as a counterpart of the incident PAR, the lost PAR energy ratio (LPR) in the atmosphere is much more directly related with absorption processes than the incident PAR. Therefore, the LPR could also play an important role to help estimate the temporal variability of incident PAR. Unfortunately, this portion of PAR has not been extensively studied, and its dynamics are still unclear.

This study is a part of a broader research effort aimed at predicting growth of an important invasive plant, yellow starthistle (YST), Centaurea solstitialis, which is considered a noxious weed in the states of California, Idaho, Oregon, and Washington in the USA (Roche and Thill 2001). Biological control, the manipulated use of herbaceous insects to control plant growth, is an important method that is used to achieve a more sustainable control strategy for this weed, and predictive models are used to help plan and manage the use of this technology. Thus, a precise plant growth model driven by realistic environmental stimuli is a critical tool to help plan an integrated weed control program to meet the goals of area-wide weed management across entire watersheds. Therefore, it is expected that PAR estimation models will be integrated with other knowledge and approaches to improve the management of YST. The present analysis aims to (a) 
investigate seasonal and diurnal patterns of PAR-related values (PPFD, PARE, fE, fFEC, LPR) during the primary plant growing season in northern California and (b) develop models to precisely estimate hourly PAR values along the coastal area of northern California. If successful, this will aid in the wider improvement and application of YST growth models that are to be used in the integrated management of this and other noxious weed species.

\section{Measurement site and data analysis}

\subsection{Study area}

The primary field study site was located on a grassdominated hill slope with moderate densities of YST. The study site was adjacent to Chabot Regional Park located near the City of Moraga, California in the San Francisco Bay region of the USA. The climate at the site is Mediterranean and is characterized by a winter rainy season (usually beginning in October) followed by a prolonged dry season (starting in March or April). The climate is further modified by the influence of marine factors that causes cooler summers and warmer winters, along much of the coastline and adjacent low-lying areas. During the dry season, a periodic fog often forms due to an emergent marine layer that inundates the land at night and dissipates during midday. The experimental period (March through August) represents the main growing season for YST, even though seeds begin germinating with the winter rains; however, cool temperatures typically limit excessive vegetative growth. Therefore, the field aspects of this study focused on the dry spring and summer season (March to August), coinciding with the time of rapid YST growth.

\subsection{Measurements and methodology}

The study was conducted over two growing seasons (spring through summer) of 2007 and 2008. During 2007, PAR data were collected from sunrise to sunset 1 day every 2 weeks, from June through August; in 2008, the PAR data were collected from sunrise to sunset on 2 days every week, from March through August. The photosynthetic photon flux density was measured with a linear AccuPAR LP-80 Ceptometer (Decagon Devices, Pullman, WA, USA), which outputs data in photobiological units of micromoles per square meter per second. The ceptometer, which measures light in the 400-700-nm wavebands across 80 sensors embedded along an $84-\mathrm{cm}$ probe, was set to automatically collect PPFD measurements every $15 \mathrm{~min}$. This instrument has an error of $\pm 3 \%$ for common light sources including the sun. Additional climatic data were downloaded from the website of California Irrigation Management Information
System, a state governmental agency in region. The data were collected at a weather station located in Moraga, CA, USA (about $2 \mathrm{~km}$ from the experimental site) and included an hourly global solar radiation $\left(R_{\mathrm{S}}\right.$, measured on a horizontal surface with a Li-Cor Pyranometer model LI200S, with an error up to 5\% under natural sunlight conditions), vapor pressure, air temperature, precipitation, relative humidity, and dew point temperature. Given the proximity $(2 \mathrm{~km})$ and topographic similarity between the weather station and the experimental site, climatic parameters measured at the weather station were highly similar to those occurring at the experimental site. Due to cosine response issues of the instrumentation, this analysis is limited to cases with solar elevation angles $h>12^{\circ}$ (i.e., $0.21 \mathrm{rad})$. The hourly data were further checked for inconsistencies to eliminate problems associated with questionable measurements.

Hourly and daily geometric parameters were estimated (see "Appendix") to supplement the AccuPAR LP-80 ceptometer data. Longitude and latitude $(-122.12 \mathrm{~W}$, $37.84 \mathrm{~N}$ ) of the experimental site were used to calculate extraterrestrial solar radiation, sunrise and sunset times, day-length, and day angle for the field location. The declination angle, the solar angle, and the solar elevation angle were calculated for the middle of each local solar hour and used to relate the calculated and corresponding observed values during each hourly sampling period. We also included the clearness index, $K_{\mathrm{t}}$ (the ratio of the globalto-extraterrestrial solar radiation), in our assessments as it accounts for the attenuation of solar radiation by most atmospheric constituents. Moreover, $\mathrm{fE}$ at the top of the atmosphere was assumed to be $40 \%$ of global solar radiation (Monteith and Unsworth 1990).

PPFD were approximately integrated using the following formula:

$\mathrm{PPFD}=\sum_{i=1}^{n}\left(f_{\mathrm{PAR}} \times \Delta T\right)$

where $f_{\mathrm{PAR}}$ is an instantaneous PPFD reading from the LP80 Ceptometer over the time interval $\Delta T$. This sampling interval accounted for the time required to obtain one reading, and thus, $n$ is the number of intervals in an hour. The unit of an instantaneous PPFD reading is micromoles per square meter per second. Hourly PPFD values are given in moles per square meter per hour $\left(1 \mathrm{~mol}=10^{6} \mu \mathrm{mol}\right)$, while daily PPFD values are expressed in moles per square meter per day.

Conversion of PAR from a photon flux to an energy unit requires detailed spectral and solar radiation data that is expensive to collect. For simplicity, McCree's conversion factor $4.57 \mathrm{\mu molJ}^{-1}$ (McCree 1972; Jones et al. 2003) was used to convert hourly PAR photon flux into its energy 
alternative (i.e., PARE). This conversion factor is a conservative quantity when used under various atmospheric conditions (McCartney 1978; Jacovides et al. 1997). In the present analysis, it was preferred to engage such a constant conversion factor centered at $550 \mathrm{~nm}$ across the wavelength range of PAR wavelength limits. After translating PPFD into PARE, fE was calculated as the fraction of PARE to global solar radiation, measured at the nearby weather station. For consistency, hourly and daily PARE values are expressed in megajoules per square meter per hour and megajoules per square meter per day, respectively.

The percentage of extraterrestrial PAR energy lost in the atmosphere (LPR), in the trace of transmission, was calculated as follows:

$\mathrm{LPR}=\frac{0.4 R_{0}-\mathrm{PARE}}{0.4 R_{0}} * 100$

where $R_{0}$ is the global solar radiation at the top of the atmosphere and PARE is the energy alternative of PPFD. Within the extraterrestrial system, energy ratio of PAR to extraterrestrial solar radiation as mentioned above was assumed to be a constant value of 0.4 (Monteith and Unsworth 1990).

The fFEC values are computed as fractions of PPFD to global solar radiation $R_{\mathrm{S}}$ occurring over a measurement increment (e.g., an hour or a day). For daily fFEC, the unit was moles per megajoules, but the hourly fFEC was expressed in micromoles per joule to maintain consistency with energy units of $R_{\mathrm{S}}$ and PARE at hourly and daily scales.

Hourly PPFD (moles per square meter per hour) was summed within a day when hourly solar elevation was higher than $12^{\circ}$ to estimate the daily PPFD (moles per square meter per day). Similarly, the daily global solar radiation $R_{\mathrm{S}}$, PARE, and LPR were computed by summing the individual hourly values. The daily $\mathrm{fE}$ was calculated from the daily sum of PARE divided by that of $R_{\mathrm{S}}$.

The monthly averaged PAR values and corresponding standard errors were used to assess diurnal trends and their fluctuations with relevant PAR expressions (PPFD, fE, fFEC, and LPR) based on the comparisons of monthly averaged hourly values. The seasonal trends were determined by comparing monthly averaged hourly PAR values at the same hour between different months for the time intervals considered (March through August). To assess the diurnal pattern of a parameter in question, the different monthly averaged hourly values were compared among different hourly periods during any given day, from sunrise to sunset for each month. In March, PAR measurements were taken between 8:00 and 17:00, while for April through August, measurements were taken between 7:00 and 18:00.
Correlation analysis was used to examine associations between PAR values and selected climatic variables, including global solar radiation, air temperature, relative humidity, vapor pressure, dew point temperature, solar elevation (transformed into its sine function), and the clearness index $\left(K_{\mathrm{t}}\right)$. These variables were further used to develop multiple linear models for estimating hourly PAR values. About three fourths of these hourly values $(n=345)$ were randomly selected for model calibration, while the remaining one fourth $(n=115)$ were used for model verification.

\section{Results}

3.1 Distribution of monthly mean daily PPFD, PARE, $R_{\mathrm{S}}, \mathrm{fFEC}, \mathrm{fE}$, and LPR

Over the experimental periods, averaged daily values (mean \pm $\mathrm{SE}$ ) of PPFD, $R_{\mathrm{S}}$, PARE, fFEC, fE, LPR, and $K_{\mathrm{t}}$ were $48.30 \pm 10.52 \mathrm{~mol} / \mathrm{m}^{2} /$ day, $23.87 \pm 3.89 \mathrm{MJ} / \mathrm{m}^{2} /$ day, $11.27 \pm$ $2.11 \mathrm{MJ} / \mathrm{m}^{2} /$ day, $2.16 \pm 0.08 \mu \mathrm{mol} / \mathrm{J}, 0.47 \pm 0.02,28.79 \pm$ $6.85 \%$, and $0.60 \pm 0.01$, respectively. It was further found that daily values of $\mathrm{fFEC}$ and $\mathrm{fE}$ were very conservative, although not constant. The stand error of $K_{\mathrm{t}}$ was slightly greater than $1 \%$ of its mean, suggesting that sky conditions were rather consistent during the experimental periods. For the other parameters, standard errors were greater than $5 \%$ of the corresponding means, except for fFEC (3.70\%) and $\mathrm{fE}(4.26 \%)$. In March, the monthly averaged daily values of PPFD, $R_{\mathrm{S}}$, PARE, fE, and fFEC were at their lowest levels during the growing seasons; they increased from April and reached their peaks in June around the summer solstice, then decreased through July. In contrast, LPR exhibited the opposite trend, highest in March (41.37\%) and lowest in June $(21.76 \%)$. The monthly mean of the daily distributions of PPFD, PARE, global solar radiation $R_{\mathrm{S}}$, fFEC, fE, and LPR is presented in Fig. 1. The monthly mean daily PPFD varied between $30.28 \pm 6.3$ (the average in March) and $59.91 \pm 7.50 \mathrm{~mol} / \mathrm{m}^{2}$ (the average in June). The monthly mean daily PARE (Fig. 1b) closely followed PPFD, ranging from $7.58 \pm 1.37$ (in March) to $13.51 \pm 2.08 \mathrm{MJ} / \mathrm{m}^{2}$ (in June). Global solar radiation (Fig. 1c) exhibited a seasonal pattern similar to that of PPFD and PARE, reaching its minimum in March and its maximum in June. Figure 1d, e further reveals that both fractions, fFEC and $\mathrm{fE}$, provide a relatively conservative pattern over the time interval considered in this study, a finding that supports earlier research (Stigter and Musabilha 1982; Papaionnou et al. 1993). fFEC ranged from 2.01 (in March) to $2.23 \mathrm{~mol} \mathrm{MJ}^{-1}$ (in June), with an annual mean daily value of $2.11 \mathrm{molMJ}^{-1}$, whereas the respective $\mathrm{fE}$ ratio values varied between 0.44 (in March) and 0.48 (in June), resulting in an overall mean 
a

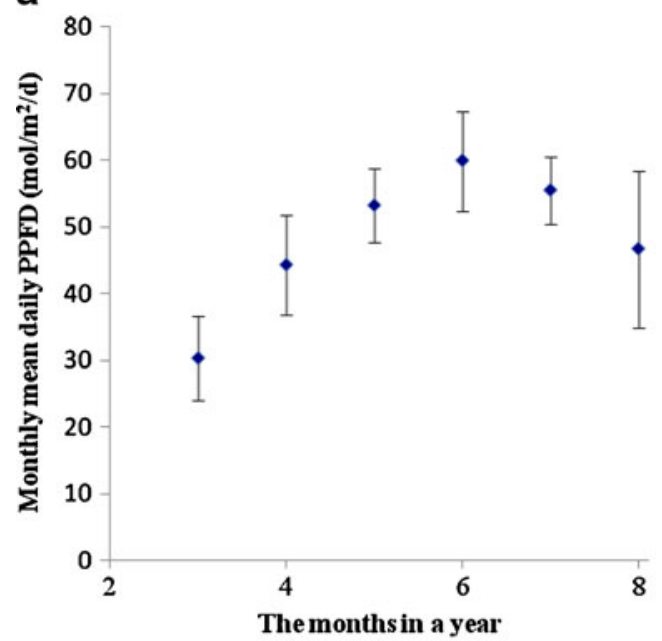

b

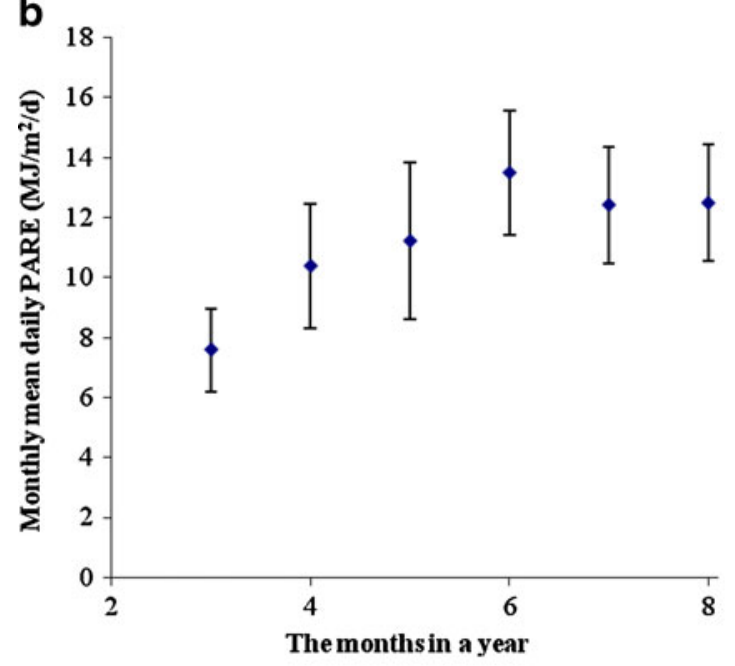

C

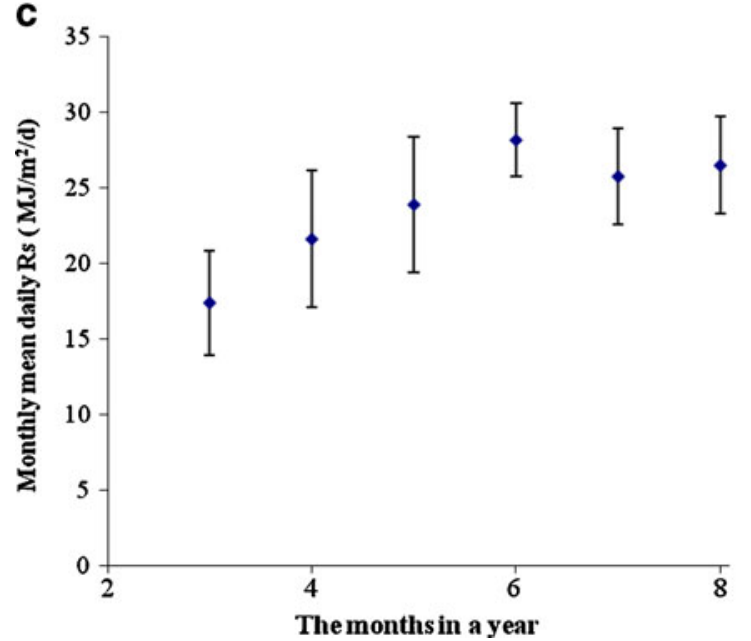

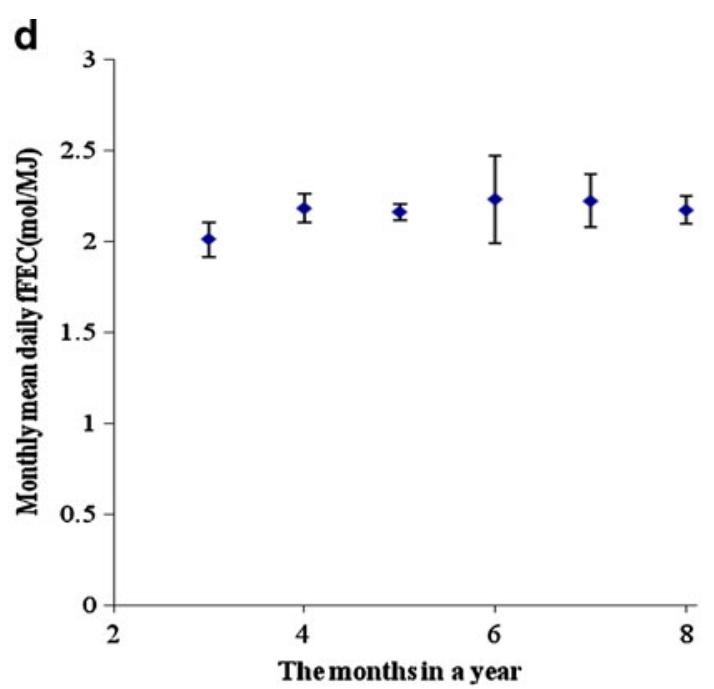

e

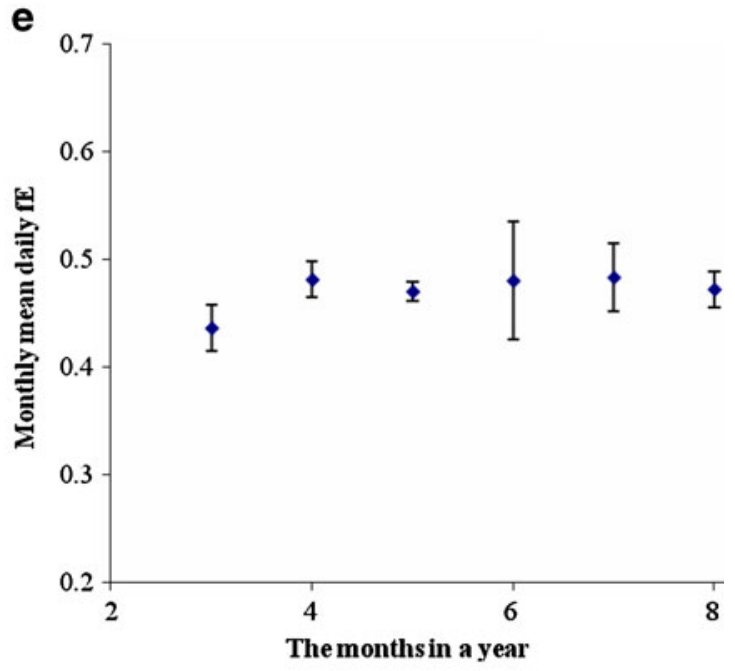

f

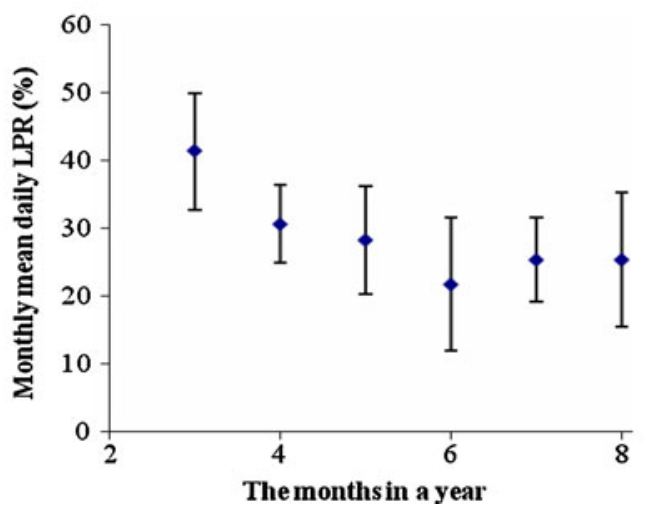

Fig. 1 Distribution of monthly means of daily PAR-related values: for a PPFD, $\mathbf{b}$ PARE, $\mathbf{c} R_{\mathrm{S}}, \mathbf{d}$ fFEC, $\mathbf{e}$ fE, and $\mathbf{f} L P R$. Data are means \pm standard error 
daily ratio of about 0.46 . The monthly mean daily LPR was the highest at the beginning of the experimental season and again toward the end of the dry season. The maximum LPR was observed in March and the minimum in June.

\subsection{Diurnal patterns of monthly mean hourly PAR-related values}

The monthly averages of hourly PAR values exhibited strong diurnal patterns (Fig. 2). Although fE and fFEC had very conservative daily values when considered on a monthly basis, both exhibited significant variability over the course of a day. The diurnal differences of PAR among local hours across a day from sunrise to sunset were higher than that of monthly differences between the same local hours of different months. Values of PPFD, PARE, fE, and fFEC were typically low in the early morning, approached their peaks around the noon hour, and then decreased toward the later afternoon hours. The average hourly PPFD values (Fig. 2a) recorded at 12:30 (average between 12:00 and 13:00 LST) varied from 4.72 in March to $7.49 \mathrm{molm}^{-2}$ $\mathrm{h}^{-1}$ in June, whereas the average hourly PARE values (Fig. 2b) at the same time period ranged from $1.025 \mathrm{MJm}^{-2}$ $\mathrm{h}^{-1}$ in March to $1.63 \mathrm{MJm}^{-2} \mathrm{~h}^{-1}$ in June. The means of fFEC (Fig. 2d) ranged from 2.145 in March to $2.385 \mu \mathrm{mol}$ $\mathrm{J}^{-1}$ in August. Over the experimental period, and the overall mean hourly value of fFEC was $2.17 \mu \mathrm{molJ}^{-1}$. The corresponding values of $\mathrm{fE}$ (Fig. 2e) varied between 0.47 in March and 0.52 in July, whereas the overall mean hourly value was 0.49 . Finally, the LPR values (Fig. $2 \mathrm{f}$ ) at noon oscillated between 33\% in March and 12\% in July. Both PPFD and PARE exhibited diurnal trends that were similar to that of global solar radiation (Fig. 2c), further suggesting that PPFD and PARE are likely to be associated with the dynamical status of the global solar radiation field. When values of $\mathrm{fE}$ and $\mathrm{fFEC}$ were evaluated from hour-to-hour to capture diurnal patterns, they were found to vary with daytime hours following the solar elevation angles. In addition, on the basis of standard errors of the hourly means, $\mathrm{fE}$ was found to be relatively constant, as its SE was always less than $5 \%$. Other PAR-related quantities (LPR, $R_{\mathrm{S}}$, PARE) were more variable, even on an hourly basis. Considering these observations, it was found that PARrelated variables may be (a) sensitive to changes in solar zenith angle (local time) and (b) comprehensively affected by meteorological parameters such as air turbidity, clouds and/or fog formation, other water vapor, and aerosol loadings.

\subsection{Proposed parametric models for both PPFD and LPR}

Using these collected data, we developed two empirical parametric models. These models employed a multiple linear regression approach to select significant variables from available weather data and calculated geometrics of PAR values as given in "Appendix". We constructed the models using the best subset approach to determine the required variables from the list of potential predictors given in Table 1 by assessing their impacts on the overall variability explained by the model. The most explanatory parameters in the model were global solar radiation, solar elevation, and the clearness index (Table 1).

For the hourly values of photosynthetic photon flux density, the best results were obtained through the expression:

$$
\begin{gathered}
\text { PPFD }=-0.1248+0.0069 R_{\mathrm{S}}+0.0035 R_{\mathrm{S}} \sin (h)-0.0024 R_{\mathrm{S}} K_{\mathrm{t}} \\
\left(n=345, R^{2}=0.95, p=0.01\right)
\end{gathered}
$$

where PPFD is the hourly photon flux density (moles per square meter per hour), $R_{\mathrm{S}}$ is the hourly global solar radiation (watts per square meter), $h$ is the solar elevation angle, and $K_{\mathrm{t}}$ is the clearness index. It is interesting to note that the inclusion of air and/or dew temperature, vapor pressure, or relative humidity did not improve the model's performance.

We subjected the model to verification using an independent subset $(n=115)$ of the data. Figure 3 displays experimental PPFD values versus predicted values. The proposed model predicted the measured PPFD values quite accurately $\left(R^{2}=0.95, n=115, p<0.0001\right)$. From the regression line presented in Fig. 3, it can be seen that the predicted PPFD flux is very close to the measured flux, possessing an offset as low as $0.083 \mathrm{~mol} / \mathrm{m}^{2} / \mathrm{h}$ and a slope of up to 0.95 . This further suggests that the hourly PPFD can be precisely estimated from the global solar radiation $\left(R_{\mathrm{S}}\right)$ along with the clearness index $\left(K_{\mathrm{t}}\right)$ and solar elevation angle $(h)$.

The same procedure was used to model hourly LPR values. The optimal model treated $K_{\mathrm{t}}$ as the effective parameter and also included the interaction of $K_{\mathrm{t}}$ with solar elevation angles. The most predictive model of LPR was:

LPR $=0.9636-0.6761 K_{\mathrm{t}}-0.5913 K_{\mathrm{t}} \sin (h)$

where LPR is the ratio of PAR energy lost in the atmosphere, to PAR energy at the top of the atmosphere.

As with PPFD, the independent subset $(n=115)$ of the original data was used to verify the accuracy of the proposed model (Eq. 4). Figure 4 compares experimental LPR values versus predicted ones through the proposed model (Eq. 4). The proposed model predicted accurately the measured LPR values (Fig. 4); however, the relationship was not as strong as for PPFD $\left(R^{2}=0.85, p<0.0001, n=\right.$ 115). The model had an offset of about 0.073 and a slope up to 0.86 , implying that the model overestimates LPR by $7.3 \%$. 


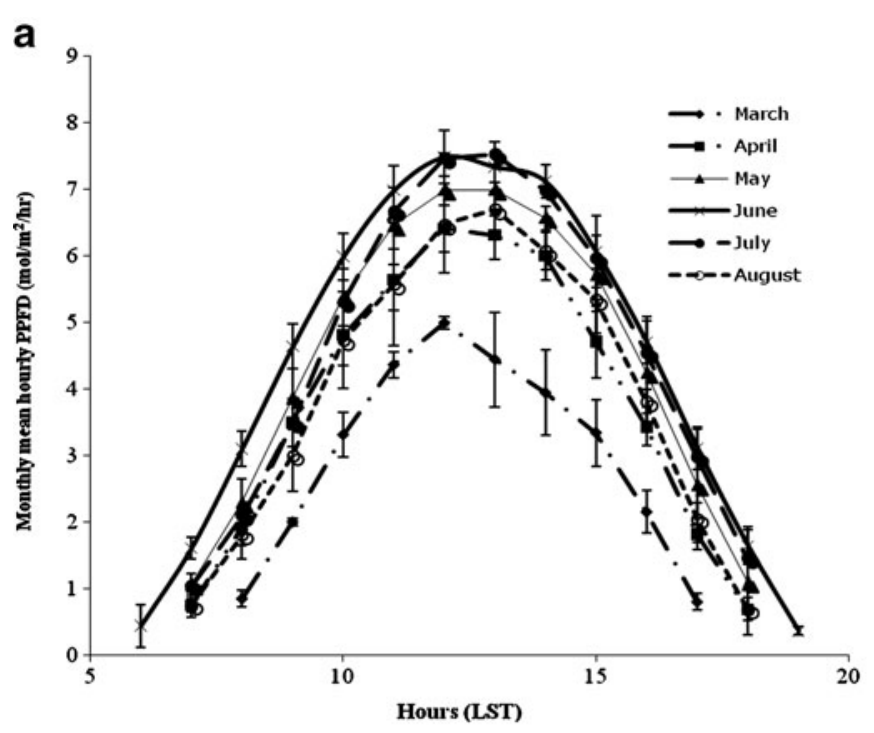

d
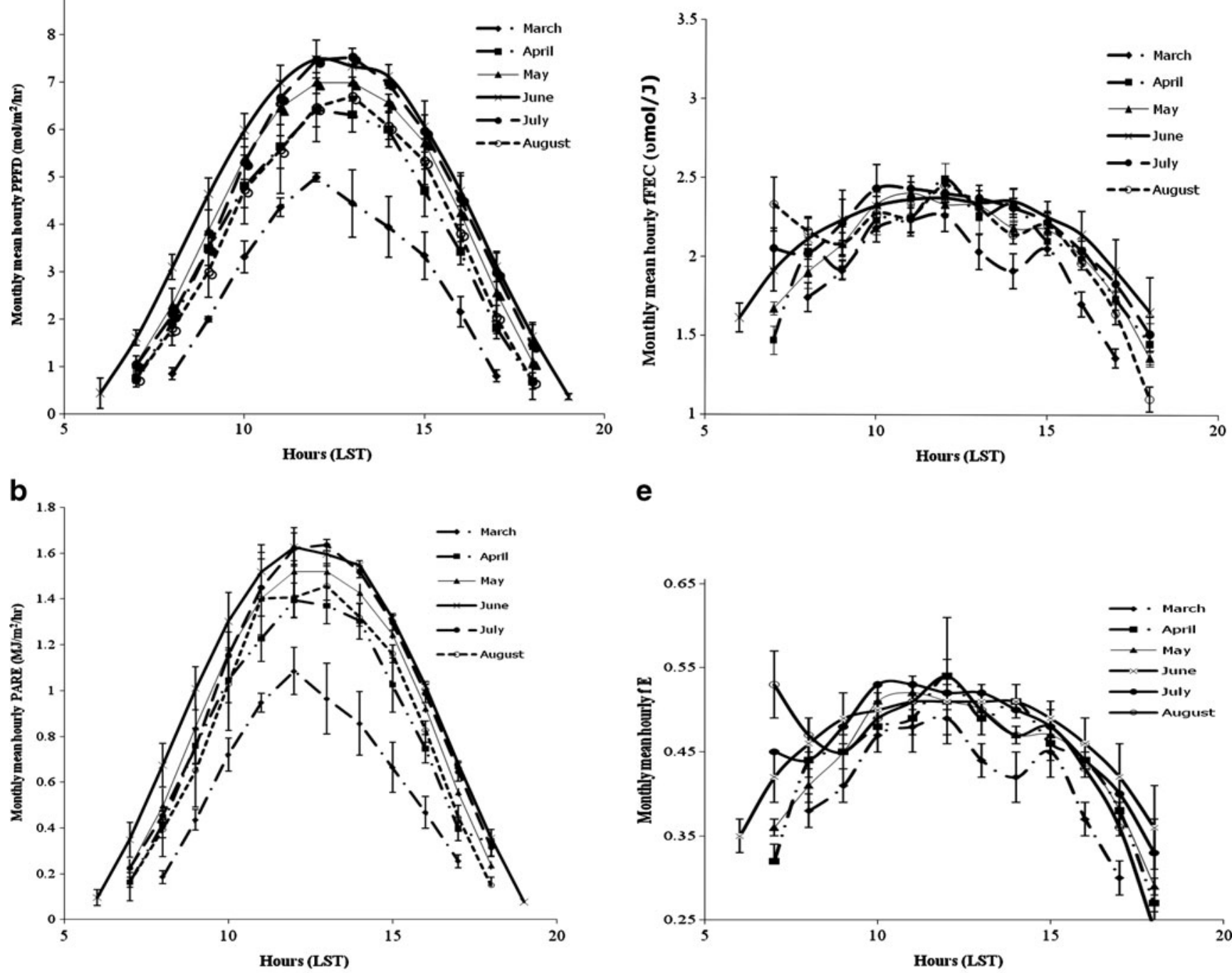

e
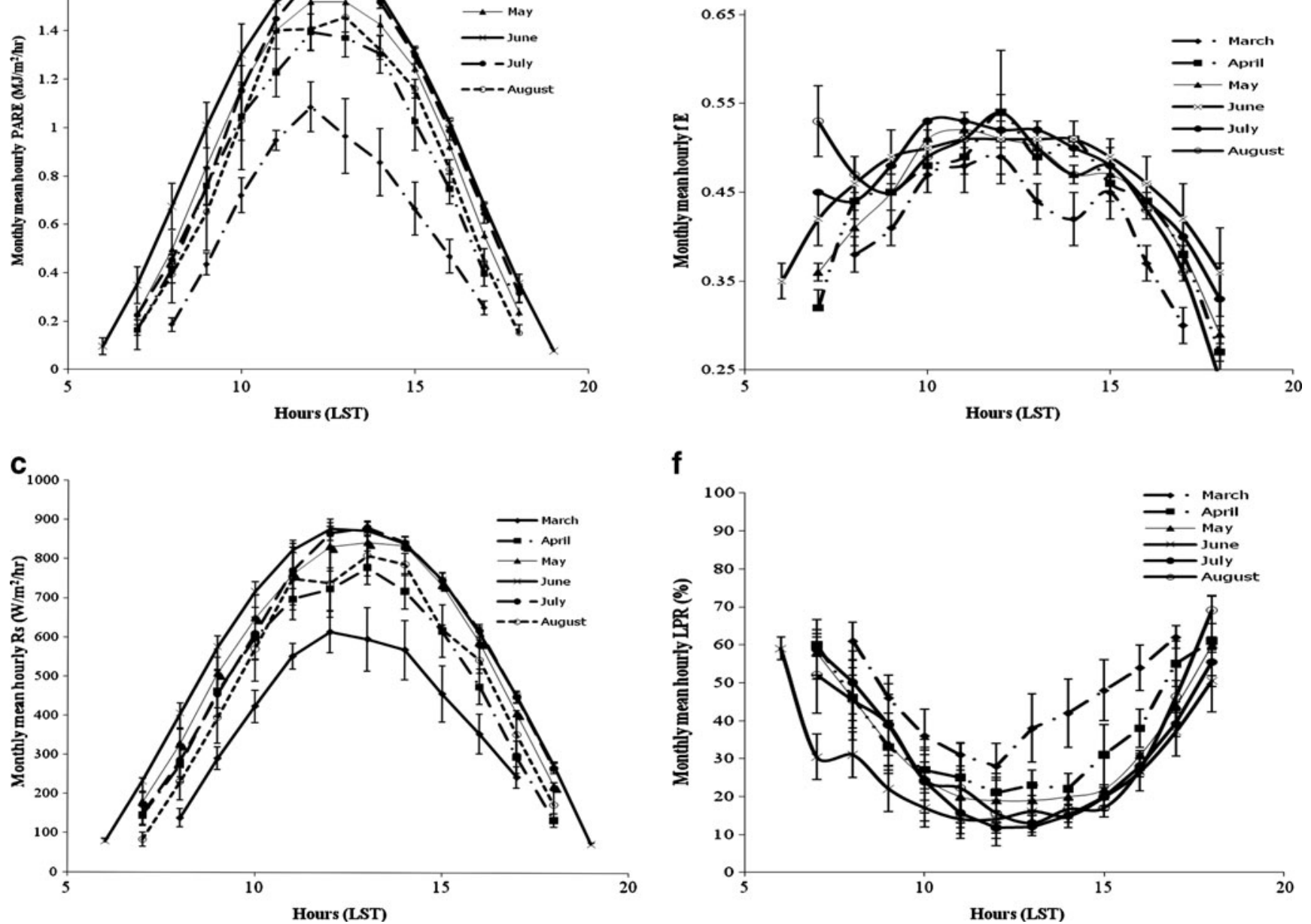

Fig. 2 Monthly mean hourly values for a PPFD, b PARE, $\mathbf{c} R_{\mathrm{S}}, \mathbf{d} \mathrm{fFEC}$, e for fE, and $\mathbf{f}$ for LPR. Data are means \pm standard error 
Table 1 Significant correlation coefficients $(r)$ of four PARrelevant values when compared with locally measured weather variables $(n=460, p \leq 0.01)$

\begin{tabular}{llll}
\hline & PPFD & LPR & fE or fFEC \\
\hline Sin(solar elevation)/solar elevation & $0.93 / 0.92$ & $-0.72 /-0.73$ & $0.61 / 0.62$ \\
Ground solar radiation & 0.97 & -0.87 & 0.53 \\
$K_{\mathrm{t}}$ & 0.70 & -0.85 & 0.13 \\
Vapor pressure & & -0.15 & 0.21 \\
Air temperature & 0.45 & -0.40 & 0.18 \\
Relative humidity & -0.42 & 0.35 & \\
Dew point temperature & & & 0.19 \\
\hline
\end{tabular}

In addition, we used a data set collected at Athens, Greece to verify these two models across geographical locations. The results demonstrated that these two models performed very well (Fig. 5) in independent locales. Therefore, we expect that they could be extended in many different places, far away from the original study site.

\section{Discussion}

\subsection{Variability of PAR values}

Both $\mathrm{fE}$ and fFEC are two important characteristics of PAR because they are closely related to light use efficiency in plant growth (McCree 1972; Papaionnou et al. 1993; Alados et al. 1996). They also have important implications for global climate change and other environmental issues (Hanan et al. 2002). Therefore, they were the main focuses for similar earlier studies (Udo and Aro 1999; Tsubo and Walker 2005). Across a range of latitudes, averages of $\mathrm{fE}$ have been shown to vary between 0.43 and 0.49 , with individual values ranging from 0.41 to 0.52 when PAR was defined as sunlight waveband between 0.4 and $0.7 \mu \mathrm{m}$

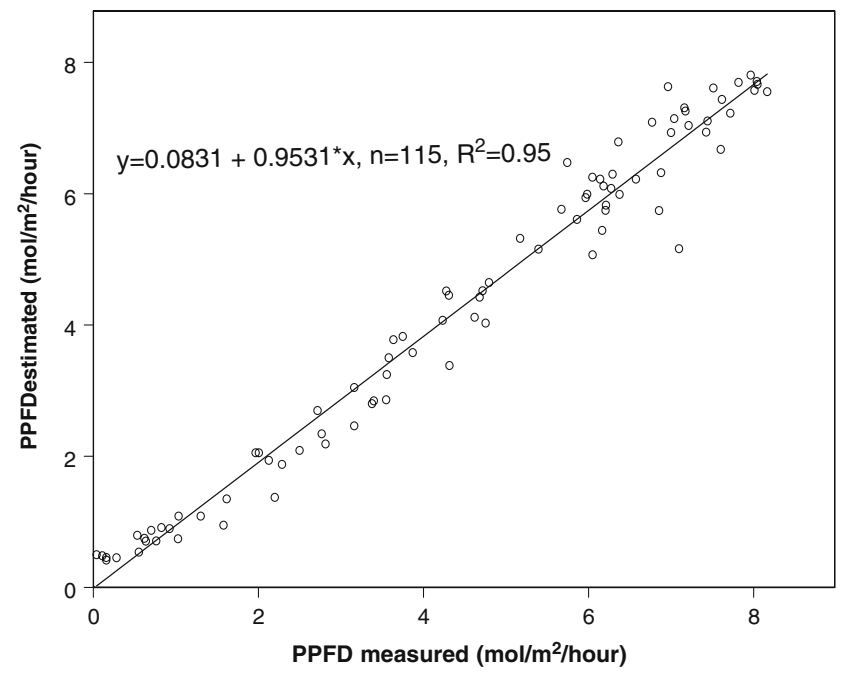

Fig. 3 Verification results for the proposed parametric model used for predicting PPFD
(Kvifte et al. 1983; Tsubo and Walker 2005). Within a season, the daily ratios may change only slightly from day to day, or even from month to month (Udo and Aro 1999). In most studies, therefore, daily $\mathrm{fE}$ has been assumed to be relatively constant across latitudes, diurnally, and temporally (Williams 1976). Similarly, Jacovides et al. (2007) reported that seasonal fFEC changed only slightly from $2.006 \mathrm{~mol} / \mathrm{MJ}$ in winter to $1.989 \mathrm{~mol} / \mathrm{MJ}$ in summer, with an annual mean of $1.995 \mathrm{~mol} / \mathrm{MJ}$. In this analysis, we found that the seasonal differences of $\mathrm{fE}$ and $\mathrm{fFEC}$, on a daily basis, were not as large as those recorded on an hourly basis, suggesting that the time scale considered has important implications for the conversion of fFEC and $\mathrm{fE}$. Therefore, we imagine that plant growth models that use PAR would provide more precise estimation of vegetative production when the diurnal patterns of PAR are considered, due to apparent changes of PARrelated values during a daily time course, assuming that other given model driven factors are fixed.

\subsection{Fog effects on PAR radiation}

The frequent occurrence of dense fog over the experimental site was a common climatic characteristic observed during the time intervals examined here. It is known that

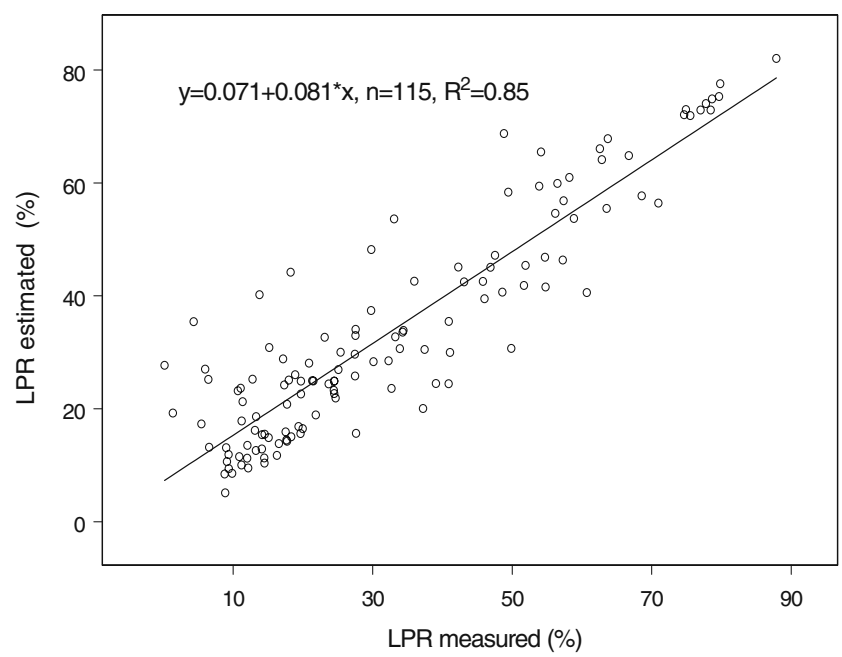

Fig. 4 Verification results for the proposed parametric model used for predicting LPR. The regression line is shown 
a

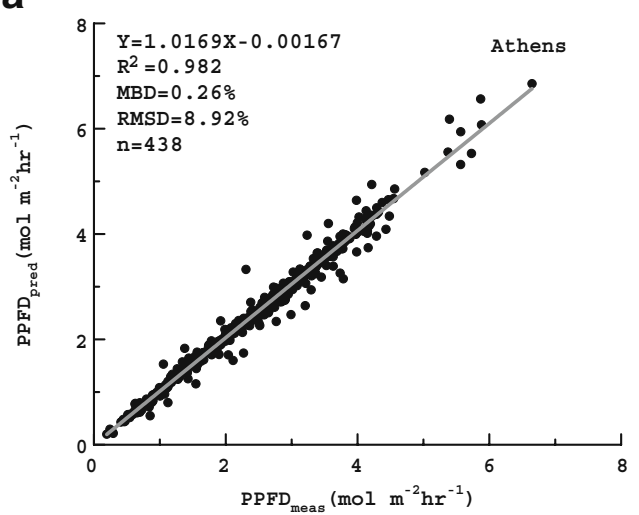

b

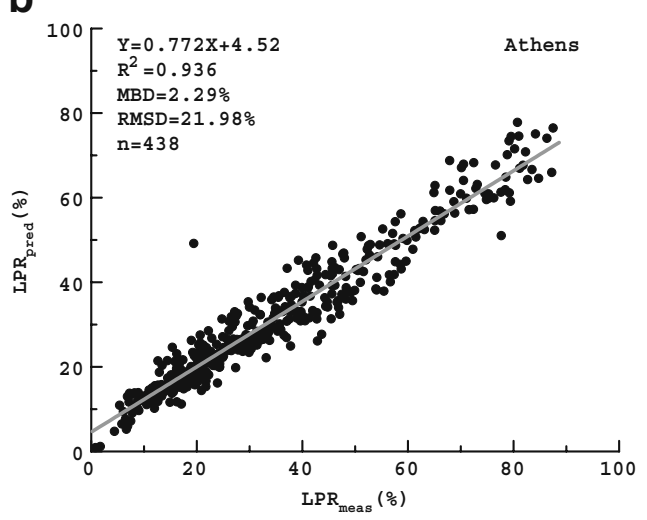

Fig. 5 Long-distance verification of the two models a PPFD and $\mathbf{b}$ LPR constructed from data collected near San Francisco, CA, USA and tested in Athens, Greece

suspended particles in the atmosphere, such as aerosol particles and fog droplets, can scatter and absorb solar radiation in the visible wavelengths. It also is well-known that aerosol activation is the process leading to fog formation. Scattering and absorption depend on particle number and properties (size and shape) that in turn are related to both dynamic and thermodynamic processes occurring at particular spatial and temporal scales, which may themselves further modify particle number and size (Elias et al. 2006).

The effect of fog is clearly seen in the diurnal course of $\mathrm{fE}$ and fFEC ratios (Fig. 2d, e), which is further dependent on light level, solar elevation angle, and fraction of direct versus diffuse light (Monteith and Unsworth 1990). That is, when light levels are already low during times of dense fog, there is up to $50 \%$ (and potentially more) loss of PAR radiation through this aerosol distribution. Not only is there more aerosol-induced extinction of PAR radiation but also the overall incoming solar radiation is reduced by a similar proportion under these conditions. Eugster et al. (2006) reported that during dense fog conditions, PPFD was only $47 \%$ of the values observed at the same time of a day under fog-free conditions. Figure 2 suggests that fog extinction was uniform over the site domain for both morning and afternoon hours, when present.

The findings in this analysis suggest that both $\mathrm{fE}$ and fFEC values were heavily affected by fog. In the early morning during summer (June through August), fE and fFEC were often higher than the corresponding values in any other month. At the same time, the corresponding global solar radiation was lower; therefore, the resulting PPFD and PARE were also lower. Nevertheless, in a recent study, Wang et al. (2009) reported that atmospheric aerosol loadings have increased globally during the past three decades. Such a phenomenon could result in a decrease of global solar radiation; however, global solar radiation may also vary regionally in response to economic development and environmental regulation (Wild 2009) via pollution levels. Despite these findings, it remains unclear how both $\mathrm{fE}$ and fFEC would be affected.

Another important consideration of the effects of fog is the discrimination of fFEC and $\mathrm{fE}$ values under various sky conditions. In this analysis, no clear effect on these ratios was determined through categorization of observed sky conditions. In this situation, a more likely scenario is that the presence of dense fog masks sky vault-induced resultant cloud cover effects and their impacts on the ground radiant fluxes and consequently on those fractions.

\subsection{Generality of our findings within the context of previous work}

Our results are generally in line with previous work conducted across the globe (Table 2) and illustrate the need for local calibration of fFEC to account for local climatic differences. Table 2 reveals the extent of important site-tosite variation in $\mathrm{FFEC}$ and its measurement. Our observed hourly mean ratio (fFEC) value of 2.17 (micromoles per joule) compares well to those reported elsewhere (Table 2). In addition, results reported by Rao (1984), Papaionnou et al. (1993), Udo and Aro (1999), and Jacovides et al. (2004) for cloudy sky conditions are also in line with our findings. This further reveals that foggy conditions have the same effect on solar radiation transmission, as those caused by cloudy sky conditions. Further, results reported under cloudy sky conditions by Howel et al. (1983), Meek et al. (1984), and Hodges and Kanemasu (1977) for various sites in the USA are also in line with the daily fFEC values that we observed in our study. It also is notable that daily averaged data from Nigeria collected under cloudy conditions by Udo and Aro (1999) also agree well with our findings.

\subsection{Predicting PAR values}

PAR exerts important effects on the eco-physiological characteristics of plants. In the literature, several models 
Table 2 Ratios of photon flux density to global solar radiation (fFEC) at different worldwide locations

\begin{tabular}{|c|c|c|c|c|c|c|}
\hline \multicolumn{2}{|l|}{$Q_{\mathrm{P}} / R_{\mathrm{S}}$} & \multicolumn{2}{|l|}{ Cloudiness } & \multirow[t]{2}{*}{ Location } & \multirow[t]{2}{*}{ Method } & \multirow[t]{2}{*}{ References } \\
\hline Hourly $\left(\mu \mathrm{mol} \mathrm{J}^{-1}\right)$ & Daily $\left(\mathrm{molMJ}^{-1}\right)$ & Hourly & Daily & & & \\
\hline & 2.17 & & & Manhattan, Kansas & $\mathrm{D}$ & Hodges and Kanemasu (1977) \\
\hline \multirow[t]{3}{*}{$\begin{array}{l}2.33 \\
2.88\end{array}$} & & $\begin{array}{l}\text { Clear } \\
\text { Cloudy }\end{array}$ & & Dar as Salaam, Tanzania & $\mathrm{I}$ & Stigter and Musabilha (1982) \\
\hline & 2.052 & & & California & $\mathrm{D}$ & Howel et al. (1983) \\
\hline & $\begin{array}{l}2.15 \\
2.04\end{array}$ & & Cloudy & $\begin{array}{l}\text { Fresno, CA } \\
\text { Fresno, CA }\end{array}$ & $\mathrm{D}$ & Meek et al. (1984) \\
\hline 2.207 & & Cloudy & & Corvallis, Oregon & I & Rao (1984) \\
\hline \multirow[t]{3}{*}{$\begin{array}{l}2.139 \\
2.24\end{array}$} & 2.157 & $\begin{array}{l}\text { Clear } \\
\text { Cloudy }\end{array}$ & $\begin{array}{l}\text { Clear } \\
\text { Cloudy }\end{array}$ & Athens, Greece & I & Papaionnou et al. (1993) \\
\hline & $\begin{array}{l}1.874 \\
2.011\end{array}$ & & $\begin{array}{l}\text { Clear } \\
\text { Cloudy }\end{array}$ & Almeria, Spain & $\mathrm{D}$ & Alados et al. (1996) \\
\hline & $1.94-2.4$ & & Clear & Nordic Countries & $\mathrm{D}$ & Olseth and Skartveit (1997) \\
\hline \multirow[t]{2}{*}{$\begin{array}{l}2.07 \\
2.15\end{array}$} & 2.08 & $\begin{array}{l}\text { Clear } \\
\text { Cloudy }\end{array}$ & & Illorin, Nigeria & $\mathrm{D}$ & Udo and Aro (1999) \\
\hline & $\begin{array}{l}1.916 \\
2.112\end{array}$ & & $\begin{array}{l}\text { Clear } \\
\text { Cloudy }\end{array}$ & Lusaka, Zambia & $\mathrm{D}$ & Finch et al. (2004) \\
\hline 2.197 & 2.01 & Cloudy & Cloudy & Nicosia, Cyprus & $\mathrm{D}$ & Jacovides et al. (2004) \\
\hline $\begin{array}{l}1.995 \\
2.106 \\
1.991\end{array}$ & Spring & $\begin{array}{l}\text { Clear } \\
\text { Cloudy }\end{array}$ & & Athens, Greece & $\mathrm{D}$ & Jacovides et al. (2007) \\
\hline 1.999 & Summer & & & & & \\
\hline 2.17 & 2.16 & Fog conditions & & California & $\mathrm{D}$ & Present work \\
\hline $\begin{array}{l}\text { Mar. } 2.15 \\
\text { Jun. } 2.39\end{array}$ & $\begin{array}{l}2.02 \\
2.19\end{array}$ & $\begin{array}{l}\text { Mostly Clear } \\
\text { Fog conditions }\end{array}$ & & California & $\mathrm{D}$ & Present work \\
\hline
\end{tabular}

$D$ direct, $I$ indirect

have been developed to estimate PAR values, contributing to many practical applications in the area of plant physiology, biomass production, and natural illumination in greenhouses. These models range from physics-based radiation transfer models to more descriptive empirical parametric models. The physics-based models have a reasonable and reliable scientific underpinning but are often complex, owing to the difficulty in obtaining data for all of the required parameters. Thus, their detailed requirements make them difficult and costly to use, especially if they are fully developed (Alados et al. 1996). In contrast, empirical models have been shown to be both reasonable and useful in practice (Al-Shooshan 1997). Empirical models are often based on different groundbased climatic factors, including geometric parameters, and are generally in the form of multiple linear regression models. A more reliable and accurate method is to incorporate important correlated factors into optional models for more accurate estimations (Udo and Aro 1999). Some of these models force the intercept to be zero (Udo and Aro 1999; Jacovides et al. 2004). These models, although simple, may induce errors, especially when estimating values on an hourly basis. For this reason, we developed parametric models with intercepts. The intercepts might be treated as an offset, which could be derived from the trends of long-term estimates (e.g., seasonal means), rather than estimates for shorter-term time scales (e.g., hourly means). However, when forcing the estimation models through the origin, the result could remove some long-term trends in climate change. Moreover, previous models have only considered the main effects of the climatic and geometric variables, while their interactions have never been taken into consideration or incorporated into predictive models (Alados and Alados-Arboledas 1999; Tsubo and Walker 2005). We believe that these interaction terms should be included to improve model predictions.

\section{Conclusions}

Our analysis of hourly and daily measurements of photosynthetic photon flux density and related climatic variables revealed the following points:

1. PAR-related values exhibited different patterns, which changed with time scale of consideration. The monthly 
averaged values were relatively stable, but diurnal patterns clearly existed within the studied values.

2. Concerning the diurnal variability of PAR: (a) low solar elevation angles resulted in a longer slant path of the direct solar beam flux traversing the atmosphere in the spring, which led to lower radiant fraction values then higher values observed in the summer. The monthly average hourly fraction fFEC values measured at noon hours ranged from 2.15 in March to $2.39 \mu^{m o l J}{ }^{-1}$ in August, while the respective fractions $\mathrm{fE}$ at the same time varied from 0.47 in March to 0.52 in July.

3. The monthly average daily ratios of fFEC and $\mathrm{fE}$ exhibited a weak seasonal dependence, low values in the spring and high but more variable values in the summer; lowest values occurred in March $\left(2.02 \mathrm{molMJ}^{-1}\right.$ and 0.45 , respectively) and the highest values were observed in June (2.19 $\mathrm{molMJ}^{-1}$ and 0.48 , respectively). An overall mean daily value of $2.16 \mathrm{molMJ}^{-1}$ for fFEC and 0.47 for $\mathrm{fE}$ was found over the experimental period.

4. Given global solar radiation, global PAR, and other related climatic data, the hourly PPFD component seems essential for many agricultural applications and could be estimated accurately to obtain diurnal changes of PAR through empirical parametric models. In this analysis, an empirical relationship between hourly PPFD and hourly global solar radiation $R_{\mathrm{S}}$, clearness index $K_{\mathrm{t}}$, and solar elevation angle $h$ was established. Moreover, if only global solar radiation is measured, we also developed a model to estimate the lost percentages of PAR when it passed through the top of the atmosphere through it to the ground. Such a model was derived from the ground-based global solar radiation, clearness index, and solar elevation angle.

Acknowledgments This project is funded by a grant from NASA for a joint cooperative research effort on invasive species control between NASA, the University of California and USDA-ARS, and by USDA-ARS CRIS Project 5325-22000-020-00D. We thank Marie Franc for assistance with project coordination and Skye Harper for field assistance. We also appreciate the California Department of Water Resources for providing the online weather data through the California Irrigation Management Information System and the East Bay Municipal Utility District for providing access to the study site.

Open Access This article is distributed under the terms of the Creative Commons Attribution Noncommercial License which permits any noncommercial use, distribution, and reproduction in any medium, provided the original author(s) and source are credited.

\section{Appendix}

Day angle (DA):

$\mathrm{DA}=(\mathrm{JD} / 365) \times 360 \times(\pi / 180)$ where JD is Julian day, starting on January 1 and ending on December 31. In leap years, 365 in Eq. 5 is replaced by 366.

Correction factor for solar constant (CSC) is applied

$\mathrm{CSC}=I_{\mathrm{sc}} \times E_{0}$

$I_{\mathrm{sc}}=1,367 \mathrm{~W} / \mathrm{m}^{2}$ or $4,921 \mathrm{KJ} / \mathrm{m}^{2}$, while $E_{0}$ is the correction factor for the mean Sun-Earth distance; $E_{0}$ is simply approximated as (Duffie and Beckman 1980):

$E_{0}=1+0.033 \cos (\mathrm{DA})$

The intensity of solar radiation at the top of the atmosphere $\left(R_{0}\right)$ can be calculated as:

$R_{0}=\mathrm{CSC} \times \cos \left(\theta_{\mathrm{z}}\right)$

where $\theta_{z}$ is the zenith angle which is calculated through the following equation:

$\cos \left(\theta_{\mathrm{z}}\right)=\sin (\phi) \sin (\delta)+\cos (\varphi) \cos (\delta) \cos (\omega)$

where $\phi$ is the site's latitude, $\delta$ is solar declination, and $\omega$ is the hour angle.

Solar declination can be obtained as follows:

$\sin (\delta)=\sin (23.45) \times \sin \left(\frac{2 \pi(\mathrm{JD}+284)}{365}\right)$

The hourly and daily extraterrestrial solar radiations in units of megajoules per meter are determined through the following equations (Whillier 1956; Elminir et al. 2007): For hourly values:

$R_{0 \mathrm{~h}}=\operatorname{CSC}\left[\cos (\varphi) \cos (\delta) \cos \left(\omega_{i}\right)+\sin (\varphi) \sin (\delta)\right]$

Equation 11 yields extraterrestrial radiation for $1 \mathrm{~h}$ centered around the hour $\omega_{i}$.For daily values:

$$
\begin{aligned}
R_{0 \mathrm{~d}}= & \frac{24}{\pi} \operatorname{CSC} \cos (\varphi) \cos (\delta) \\
& \times\left[\sin \left(\omega_{\mathrm{S}}\right)-\left(\frac{\pi \omega_{\mathrm{S}}}{180}\right) \cos \left(\omega_{\mathrm{S}}\right)\right]
\end{aligned}
$$

where $\omega_{\mathrm{S}}$ is the sunset hour angle given as,

$\omega_{\mathrm{S}}=\cos ^{-1}(-\tan (\varphi) \times \tan (\delta))$

\section{References}

Alados I, Alados-Arboledas L (1999) Validation of an empirical model for photosynthetically active radiation. Int $\mathrm{J}$ Climatol 19:1145-1152

Alados I, Foyo-Moreno I, Alados-Arboledas L (1996) Photosynthetically active radiation: measurements and modeling. Agric For Meteorol 78:121-131

Al-Shooshan A (1997) Estimation of photosynthetically active radiation under an arid climate. J Agric Engen Res 66:9-13 
Asner GP, Wessman CA (1997) Scaling PAR absorption from the leaf to landscape level in spatially heterogeneous ecosystems. Ecol Model 103:81-97

Britton CM, Dodd JD (1976) Relationships of photosynthetically active radiation and shortwave irradiance. Agric Meteorol 17:1-7

Duffie JA, Beckman WA (1980) Solar engineering of thermal process. Wiley-Interscience, New York

Elias T, Haeffelin M, Drobinski P, Gomes L, Rangognio J, Bergot T, Chazette P, Rault J, Colomb M (2006) Particulate contribution to extinction of visible radiation: pollution, haze, and fog. Atmos Res 92:443-454

Elminir HK, Azzam YZ, Younes FI (2007) Prediction of hourly and daily diffuse fraction using neural network, as compared to linear regression models. Energy 32:1513-1523

Eugster W, Burkard R, Holwerda F, Scatena FN, Bruijnzeel LA (2006) Characteristics of fog and fogwater fluxes in a Puerto Rican elfin cloud forest. Agric For Meteorol 139:288-306

Finch DA, Bailey WG, McArthur LJB, Nasitwitwi M (2004) Photosynthetically active radiation regimes in a southern African savanna environment. Agric For Meteorol 122:229-238

Goudriaan J, van Laar HH (1994) Modelling potential crop growth processes, textbook with exercises. Kluwer Academic, Dordrecht, 238pp

Gueymard C (2000) Prediction and performance assessment of mean hourly global radiation. Sol Energy 68:285-303

Hanan NP, Burba G, Verma S, Berry JA, Suyker AE, Walter-Shea (2002) Inversion of net ecosystem $\mathrm{CO}_{2}$ flux measurements for estimation of canopy PAR absorption. Glob Change Biol 8:563574

Hodges T, Kanemasu E (1977) Modeling daily dry matter production of winter wheat. Agron J 69:974-978

Howel TA, Meek DW, Hatfiels JL (1983) Relationship of photosynthetically active radiation to short-wave radiation in the San Joaquin Valley. Agric For Meteorol 28:157-175

Jacovides CP, Timbios F, Asimakopoulos DN, Steven MD (1997) Urban aerosol and clear skies spectra for global and diffuse photosynthetically active radiation. Agric For Meterol 87:91-104

Jacovides CP, Timvios FS, Papaioannou G, Asimakopoulos DN, Theofilou CM (2004) Ratio of PAR to global solar radiation measured in Cyprus. Agric For Meteorol 121:135-140

Jacovides CP, Tymvios FS, Assimakopoulos VD, Kaltsounides NA (2007) The dependence of global and diffuse PAR radiation components on sky conditions at Athens, Greece. Agric For Meteorol 143:277-287

Jones HG, Archer N, Rotenberg E, Casa R (2003) Radiation measurement for plant ecophysiology. J Exp Bot 54:879-889

Kvifte G, Hegg K, Hansen V (1983) Relationship of photosynthetically active radiation to shortwave radiation in the San Joaquin Valley. Agric Meteorol 28:157-175

Mariscal MJ, Orgaz F, Villalobos FJ (2000) Modelling and measurement of radiation interception by olive canopies. Agric For Meterol 100:183-197

McCree KJ (1966) A solarimeter for measuring photosynthetically active radiation. Agric Meteorol 3:353-366

McCree KJ (1972) Test of current definitions on photosynthetically active radiation. Agric Meteorol 10:443-453

McCartney HA (1978) Spectral distribution of solar radiation. II. Global and diffuse. Quart J R Meteorol Soc 104:911-926
Meek DW, Hatfield JL, Howell TA, Idso SB, Reginato RJ (1984) A generalized relationship between photosynthetically active radiation and solar radiation. J Agron 76:939-945

Misson L, Lunden M, McKay M, Goldstein AH (2005) Atmospheric aerosol light scattering and surface wetness influence the diurnal pattern of net ecosystem exchange in a semi-arid ponderosa pine plantation. Agric For Meteorol 129:69-83

Mohotti AJ, Lawlor DW (2002) Diurnal variation of photosynthesis and photoinhibition in tea: effects of irradiance and nitrogen supply during growth in the field. J Exp Bot 53:313-322

Monteith JL, Unsworth MH (1990) Principles of environmental physics, 2nd ed. Edward Arnold, London, United Kingdom

Mõttus M, Ross J, Sulev M (2001) Experimental study of ratio of PAR to direct integral solar radiation under cloudless conditions. Agric For Meteorol 109:161-170

Myers DR (2005) Solar radiation modeling and measurements for renewable energy applications: data and model quality. Energy 30:1517-1531

Olseth JA, Skartveit A (1997) Spatial distribution of photosynthetically active radiation over complex topography. Agric For Meteorol 86:205-214

Papaionnou G, Papanikolaou N, Retalis D (1993) Relationships of photosynthetically active radiation and shortwave irradiance. Theor Appl Climatol 48:23-27

Rao CRN (1984) Photosynthetically active components of global solar radiation: measurements and model comparison. Arch Met Geophys Bioclim Ser B34:353-364

Roche CT, Thill DC (2001) Biology of common crupina and yellow starthistle, two Mediterranean winter annual invaders in western North America. Weed Sci 49:439-447

Spitters CJT, Toussaint HAJM, Goudriaan J (1986) Separating the diffuse and direct components of global radiation and its implications for modeling canopy photosynthesis. Part I. Components of incoming radiation. Agric For Meteorol 38:217-229

Stigter CJ, Musabilha VMM (1982) The conservative ratio of photosynthetically active to total radiation in the tropics. J Appl Ecol 19:853-858

Szeicz G (1974) Solar radiation for plant growth. J Appl Ecol $11: 617-636$

Tsubo M, Walker S (2005) Relationships between photosynthetically active radiation and clearness index at Bloemfontein, South Africa. Theor Appl Climatol 80:17-25

Udo SO, Aro TO (1999) Global PAR related to global solar radiation for central Nigeria. Agric For Meteorol 97:21-31

Udo SO, Aro TO (2000) New empirical relationships for determining global PAR from measurements of global solar radiation, infrared radiation or sunshine duration. Int J Climatol 20:1265-1274

Wang K, Dickinson R, Liang S (2009) Clear-sky visibility has decreased over land globally from 1973 to 2007. Science 323:1468-1470

Whillier A (1956) The determination of hourly values of total solar radiation from daily summations. Theor Appl Climatol 7:197204

Wild M (2009) Global dimming and brightening: a review. J Geophys Res Atmos 114:D00D16. doi:10.1029/2008JD011470

Williams JG (1976) Small variation in the photosynthetically active fraction of solar radiation on clear days. Theor Appl Climatol $24: 209-217$ 